\title{
Structural Studies of Giant Viruses by Michael Rossmann
}

\section{Chuan Xiao}

The University of Texas at El Paso, El Paso, Texas, United States

Since the discovery of Mimivirus, the abundant of large dsDNA viruses in nature has led to a unique frontier of virology. Structural studies of these giant viruses, some of which have the complexities and sizes approaching to a small cell, have posed significant challenges to current techniques. Nevertheless, these studies attracted a great structural virologist, Michael Rossmann, who was a pioneer in studying virus structures. In his career, Michael had never afraid of challenges, instead, he loved to tackle them. Being one of a few scientists who first solved small protein using X-ray crystallography, Michael wanted to use it to study the structure of viruses from the very beginning, which seemed to be a mission impossible at that time. However, with great foresight and persistent hard work, many virus structures including one of the first human viruses have been determined by Michael. Now, the challenges in studying the structures of giant viruses excited Michael, making it one of his latest interests in last 20 years. Michael's group was the first group that used cryo-electron microscopy (cryo-EM) to study the structure of Mimivirus ${ }^{[1,2]}$. Even before the studies of Mimivirus, his group had already worked on several large dsDNA virus structures using both X-ray crystallography and cryo-EM. For example, a serial of structural studies of Paramecium bursaria Chlorella Virus 1 (PBCV-1) ${ }^{[3-6]}$ had established it one of the type viruses in the field, which has the most detailed structural information. It is noteworthy, the near atomic resolution structure of PBCV$1^{[7]}$ was one of those results that Michael left us in his last year. This paper again was a major breakthrough in the structural studies of giant viruses. Analyses of these structures determined by Michael's group has given rise to novel hypotheses regarding the assembly mechanism of large dsDNA viruses ${ }^{[8]}$. Michael's contributions to the structural studies of giant viruses have built a solid foundation for us and his legacy will be carried on by us in the field.

\section{References}

1. Xiao, C., P.R. Chipman, A.J. Battisti, V.D. Bowman, P. Renesto, D. Raoult, and M.G. Rossmann (2005). "Cryo-electron microscopy of the giant Mimivirus." J Mol Biol 353(3): 493-6.

2. Xiao, C., Y.G. Kuznetsov, S. Sun, S.L. Hafenstein, V.A. Kostyuchenko, P.R. Chipman, M. SuzanMonti, D. Raoult, A. McPherson, and M.G. Rossmann (2009). "Structural studies of the giant mimivirus." PLoS Biol 7(4): e1000092.

3. Yan, X., N.H. Olson, J.L. Van Etten, M. Bergoin, M.G. Rossmann, and T.S. Baker (2000). "Structure and assembly of large lipid-containing dsDNA viruses." Nat Struct Biol 7(2): 101-3.

4. Nandhagopal, N., A.A. Simpson, J.R. Gurnon, X. Yan, T.S. Baker, M.V. Graves, J.L. Van Etten, and M.G. Rossmann (2002). "The structure and evolution of the major capsid protein of a large, lipidcontaining DNA virus." Proc Natl Acad Sci U S A 99(23): 14758-63.

5. Cherrier, M.V., V.A. Kostyuchenko, C. Xiao, V.D. Bowman, A.J. Battisti, X. Yan, P.R. Chipman, T.S. Baker, J.L. Van Etten, and M.G. Rossmann (2009). "An icosahedral algal virus has a complex unique vertex decorated by a spike." Proc Natl Acad Sci U S A 106(27): 11085-9.

6. Zhang, X., Y. Xiang, D.D. Dunigan, T. Klose, P.R. Chipman, J.L. Van Etten, and M.G. Rossmann (2011). "Three-dimensional structure and function of the Paramecium bursaria chlorella virus capsid." Proc Natl Acad Sci U S A 108(36): 14837-42.

7. Fang, Q., D. Zhu, I. Agarkova, J. Adhikari, T. Klose, Y. Liu, Z. Chen, Y. Sun, M.L. Gross, J.L. Van Etten, X. Zhang, and M.G. Rossmann (2019). "Near-atomic structure of a giant virus." Nat Commun 10(1): 388. 
8. Xian, Y. and C. Xiao, Chapter Eight - Current capsid assembly models of icosahedral nucleocytoviricota viruses, in Advances in Virus Research, M. Kielian, T.C. Mettenleiter, and M.J. Roossinck, Editors. 2020, Academic Press. p. 275-313. 